\title{
Molecular Brain
}

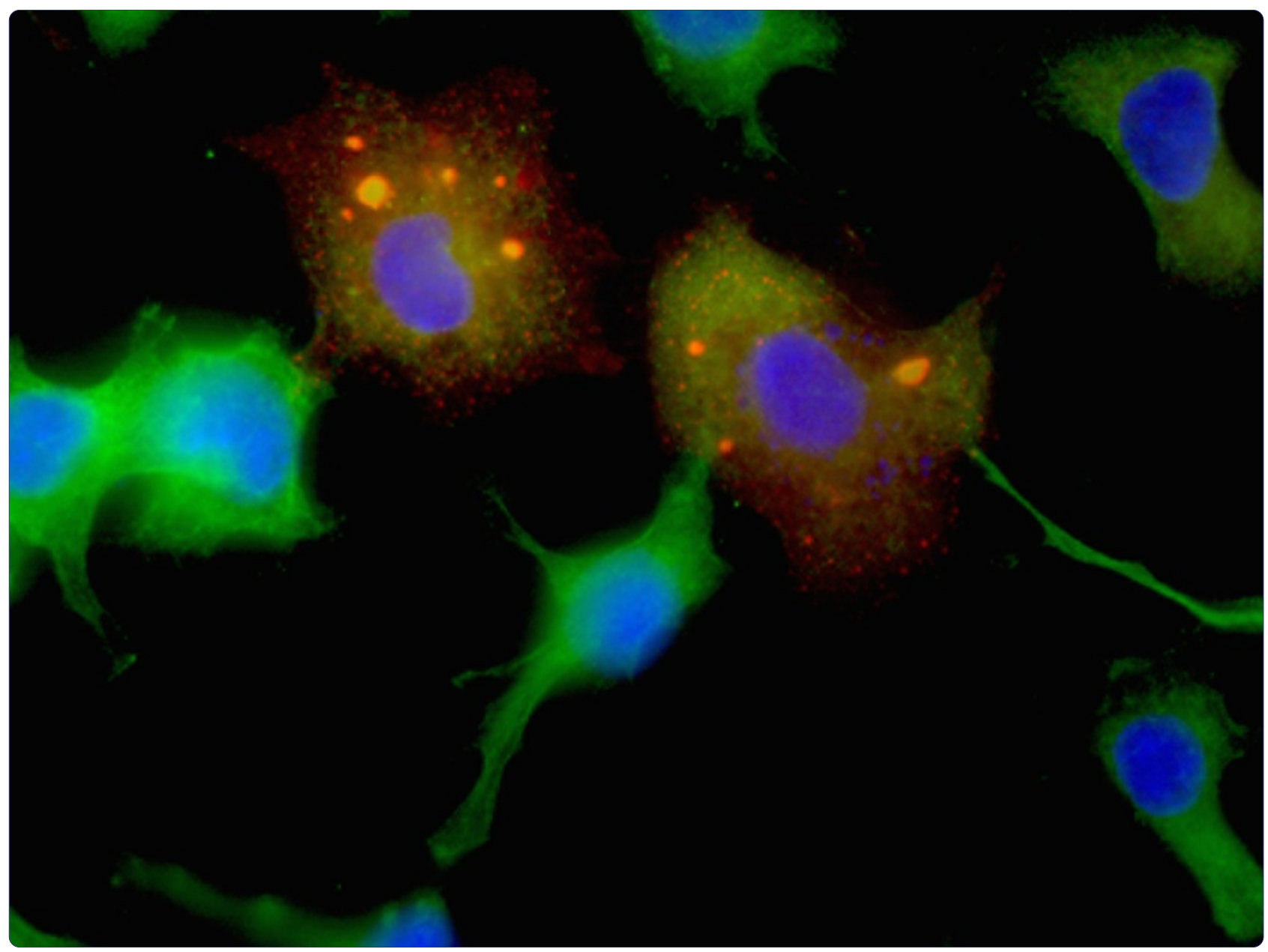

Ubiquilin-2 drives NF-kB activity and cytosolic TDP-43 aggregation in neuronal cells

Picher-Martel et al.

C BioMed Central 


\title{
Ubiquilin-2 drives NF-kB activity and cytosolic TDP-43 aggregation in neuronal cells
}

\author{
Vincent Picher-Martel ${ }^{1,2}$, Kallol Dutta $^{1,2}$, Daniel Phaneuf ${ }^{1,2}$, Gen Sobue ${ }^{3}$ and Jean-Pierre Julien ${ }^{1,2^{*}}$
}

\begin{abstract}
Background: Mutations in the gene encoding Ubiquilin-2 (UBQLN2) are linked to amyotrophic lateral sclerosis (ALS) and frontotemporal dementia (FTD). UBQLN2 plays a central role in ubiquitin proteasome system (UPS) and UBQLN2 mutants can form cytoplasmic aggregates in vitro and in vivo.

Results: Here, we report that overexpression of WT or mutant UBQLN2 species enhanced nuclear factor KB (NF-KB) activation in Neuro2A cells. The inhibition of NF-KB stress-mediated activation with SB203580, a p38 MAPK inhibitor, demonstrated a role for MAPK in NF-KB activation by UBQLN2 species. Live cell imaging and microscopy showed that UBQLN2 aggregates are dynamic structures that promote cytoplasmic accumulation of TAR DNA-binding protein (TDP-43), a major component of ALS inclusion bodies. Furthermore, up-regulation of UBQLN2 species in neurons caused an ER-stress response and increased their vulnerability to death by toxic mediator TNF-a. Withaferin A, a known NF-KB inhibitor, reduced mortality of Neuro2A cells overexpressing UBQLN2 species.

Conclusions: These results suggest that UBQLN2 dysregulation in neurons can drive NF-KB activation and cytosolic TDP-43 aggregation, supporting the concept of pathway convergence in ALS pathogenesis. These Ubiquilin-2 pathogenic pathways might represent suitable therapeutic targets for future ALS treatment.
\end{abstract}

Keywords: Amyotrophic lateral sclerosis (ALS), Ubiquilin-2 (UBQLN2), TAR DNA-binding protein 43 (TDP-43), NF-kB p65, p38 MAPK, ER-stress, Neuronal death, Withaferin A (WA)

\section{Background}

Amyotrophic lateral sclerosis (ALS) is the most common adult-onset motor neuron disorder. It is characterized by progressive degeneration of upper and lower motor neurons leading to paralysis and, unfortunately, to patient's death within 2 to 5 years. Nearly $10 \%$ of ALS cases are familial and $90 \%$ are sporadic. Expanded hexanucleotide repeats in C9orf72 account for approximately $30 \%$ of familial cases, mutations in superoxide dismutase 1 (SOD1) for $20 \%$ whereas other genes like TAR DNAbinding protein (TDP-43), fused in sarcoma (FUS), p62/ SQSTM1 and Ubiquilin-2 (UBQLN2) account for less than $10 \%$ [1]. The main pathogenic mechanisms of

\footnotetext{
* Correspondence: jean-pierre.julien@fmed.ulaval.ca

${ }^{1}$ Research Centre of Institut Universitaire en Santé Mentale de Québec, Laval University, 2601 Chemin de la Canardière, Québec, QC G1J 2G3, Canada ${ }^{2}$ Department of Psychiatry and Neuroscience, Laval University, 2601 Chemin de la Canardière, Québec, QC G1J 2G3, Canada

Full list of author information is available at the end of the article
}

ALS are still a mystery. Numerous cellular dysfunctions have been linked to ALS physiopathology including oxidative stress, protein inclusions, inflammatory processes, RNA processing and endoplasmic reticulum stress (ER-stress) [2].

Ubiquilin-2 acts as an important player in the ubiquitin proteasome system (UPS) by connecting the UPS and ubiquitinated proteins. It is also implicated in autophagy, cell cycle progression and cell signaling. UBQLN2 possesses an N-terminal ubiquitin-like domain, a C-terminal ubiquitin-associated domain and a PXX domain essential for protein-protein interaction [3]. Originally, five X-linked mutations in UBQLN2 gene have been discovered in ALS/FTD familial cases [4]. All these mutations are located in the PXX domain and one of the most frequent is $\mathrm{P} 497 \mathrm{H}$. Patients with mutant UBQLN2 ${ }^{\mathrm{P} 497 \mathrm{H}}$ develop cytoplasmic inclusions positive for major proteins implicated in ALS such as TDP-43, ubiquitin, FUS and p62. Furthermore, ALS/FTD patients 
without UBQLN2 mutation also express UBQLN2 positive inclusions, supporting an important role of this protein in ALS physiopathology [4]. More than ten UBQLN2 mutations have been currently described in ALS, not only in the PXX domain [5-8]. UBQLN2 is also implicated in other neurological disorders such as FTD [4], Alzheimer's disease [9] and Huntington's disease [10].

Nuclear Factor kappa-B (NF- $\mathrm{kB})$ is a transcription factor implicated in inflammation. NF- $\mathrm{kB}$ is formed by members of Rel/NF- $\mathrm{kB}$ family such as p50, p52, p65 (RelA), RelB or c-Rel in homo or heterodimeric complexes. The complex composed of p65 and p50 has been the most characterized. A wide variety of extracellular signals lead to NF- $\mathrm{kB}$ activation, including cytokines, infectious agents or oxidants. Almost all signals that trigger the NF- $\mathrm{KB}$ signaling pathway converge on activation of a molecular complex that contains a serine residuespecific ІкB kinase (IKK). In the classical (canonical) NF- $\kappa B$ pathway, activation of the IKK complex leads to phosphorylation mediated by IKK $\beta$ of IKB- $\alpha$, which is subsequently targeted for intracellular ubiquitination and degradation by the proteasome complex. This releases p65 NF- $\mathrm{kB}$ from IкB- $\alpha$ inhibitor and the phosphorylated $\mathrm{p} 65$ form is then transported to nucleus where it binds to specific response elements (RE) affecting transcription of various genes involved in a diversity of biological processes such as immunity, inflammatory, stress response and development [11]. NF- $\mathrm{kB}$ has an emerging role in ALS or other neurological disorders. NF- $\kappa B$ activity is increased in human neuroblastoma cells expressing mutant SOD1 ${ }^{\mathrm{G} 93 \mathrm{~A}}[12]$ and it is upregulated in motor neurons of sporadic ALS cases [13]. Our group reported previously that TDP-43 interacts with NF- $\mathrm{kB}$ and that NF- $\mathrm{kB}$ mRNA levels are abnormally up-regulated in the spinal cord of ALS patients [14]. Furthermore, NF-kB inhibition by administration of Withaferin A, a known NF-kB inhibitor, reduced ALS disease symptoms in a TDP-43 transgenic mouse model [14] and extended lifespan of mutant SOD1 ALS mice [15]. Longevity of mutant SOD1 mice was also increased by microglia-specific inhibition of NF- $\mathrm{kB}$ pathway [16]. These data suggest a central role for the NF- $\mathrm{kB}$ pathway in ALS pathogenesis.

Here, we used a NF-kB-luciferase reporter assay to examine the effect of UBQLN2 overexpression on NF- $\kappa B$ activity. We have determined that upregulation of UBQLN2 enhances NF- $\mathrm{KB}$ activation in Neuro2A cells. We also used small interference RNA (siRNA) against UBQLN2 to prevent NF- $\mathrm{kB}$ activation by UBQLN2. Treatment of transfected cells with different MAPK inhibitors suggested that NF-кB activation by UBQLN2 species resulted from p38 MAPK activation. Moreover, we found that up-regulation of
UBQLN2 protein species causes aggregation and cytoplasmic accumulation of TDP-43. Evidence is presented that UBQLN2 inclusions are dynamic structures which can increase in size over time. Finally, we report that UBQLN2 upregulation enhances ER-stress response and NF-kB-mediated neuronal vulnerability to death caused by exposure to toxic mediator TNF- $\alpha$.

\section{Results}

\section{UBQLN2 up-regulation induces NF-KB activation}

We transfected Neuro2A cells with PCMV-hUBQLN2 ${ }^{\text {WT }}$ and mutant pCMV-hUBQLN2 ${ }^{\mathrm{P} 497 \mathrm{H}}$ plasmids to determine the effects of overexpressing hUBQLN2 species on activation of NF- $\kappa B$ signaling. TNF- $\alpha$ treatment was used to trigger NF- $\mathrm{KB}$ activation and to mimic neuroinflammatory condition in ALS disease [17]. We detected a NF-kB hyper-activation in Neuro2A cells overexpressing hUBQLN2 species. Figure 1a shows a Western blot analysis of nuclear and cytoplasmic protein extracts at 48 hours after transfection. We prepared nuclear and cytosolic fractions to assess the NF- $\mathrm{KB}$ distribution in cells. According to our results, the distribution and the phosphorylation of NF- $\kappa$ B p65 in Neuro2A cells is required to precisely measure NF- $\kappa B$ activity. As compared to control cells, we observed a slight increase of nuclear phospho-p65 in hUBQLN2 ${ }^{\mathrm{WT}}$-transfected cells and a higher increase of nuclear phospho-p65 in cells transfected with hUBQLN2 ${ }^{\mathrm{P} 497 \mathrm{H}}$ after TNF- $\alpha$ treatment (Fig. 1a, b). Non-phosphorylated nuclear p65 NF-kB was equally increased in both hUBQLN2 ${ }^{\mathrm{WT}}$ and hUBQLN2 ${ }^{\mathrm{P} 497 \mathrm{H}}$. We did not observe difference in nuclear phospho-p65 without TNF- $\alpha$ treatment but we observed an increase in cytoplasmic phospho-p65 in both hUBQLN2 ${ }^{\mathrm{WT}}$ and hUBQLN2 ${ }^{\mathrm{P} 497 \mathrm{H}}$ transfected cells. We also monitored IKB- $\alpha$ phosphorylation and degradation as a marker of NF- $\mathrm{kB}$ activation. We did not observe differences in levels of phospho-IкB- $\alpha$ between control cells and hUBQLN2-overexpressing cells with or without TNF- $\alpha$ treatment. In the classical pathway of NF- $\kappa B$ activation, the phosphorylation of the IкB- $\alpha$ protein results in its ubiquitination, dissociation from NF- $\mathrm{kB}$, and eventual degradation by the proteasome. However, it has been reported that in Neuro2A cells treated with TNF- $\alpha$, IK $B-\alpha$ is phosphorylated and degraded within a short time period ( $30 \mathrm{~min}$ ) and then the levels come back to basal level within $2 \mathrm{~h}$, even if NF- $\mathrm{KB}$ remains activated [18]. Our results are consistent with this report. Moreover, an involvement of p38 MAPK in the phosphorylation and activation of p65 as substantiated below does not require IкB- $\alpha$ protein degradation.

To accurately measured the NF- $\mathrm{kB}$ activation, we performed a luciferase reporter assay in Neuro2A cells stably transfected with pGL4.32 [luc2p/NF-kB-RE/Hygro]. This plasmid contains a NF- $\mathrm{kB}$ response element which 


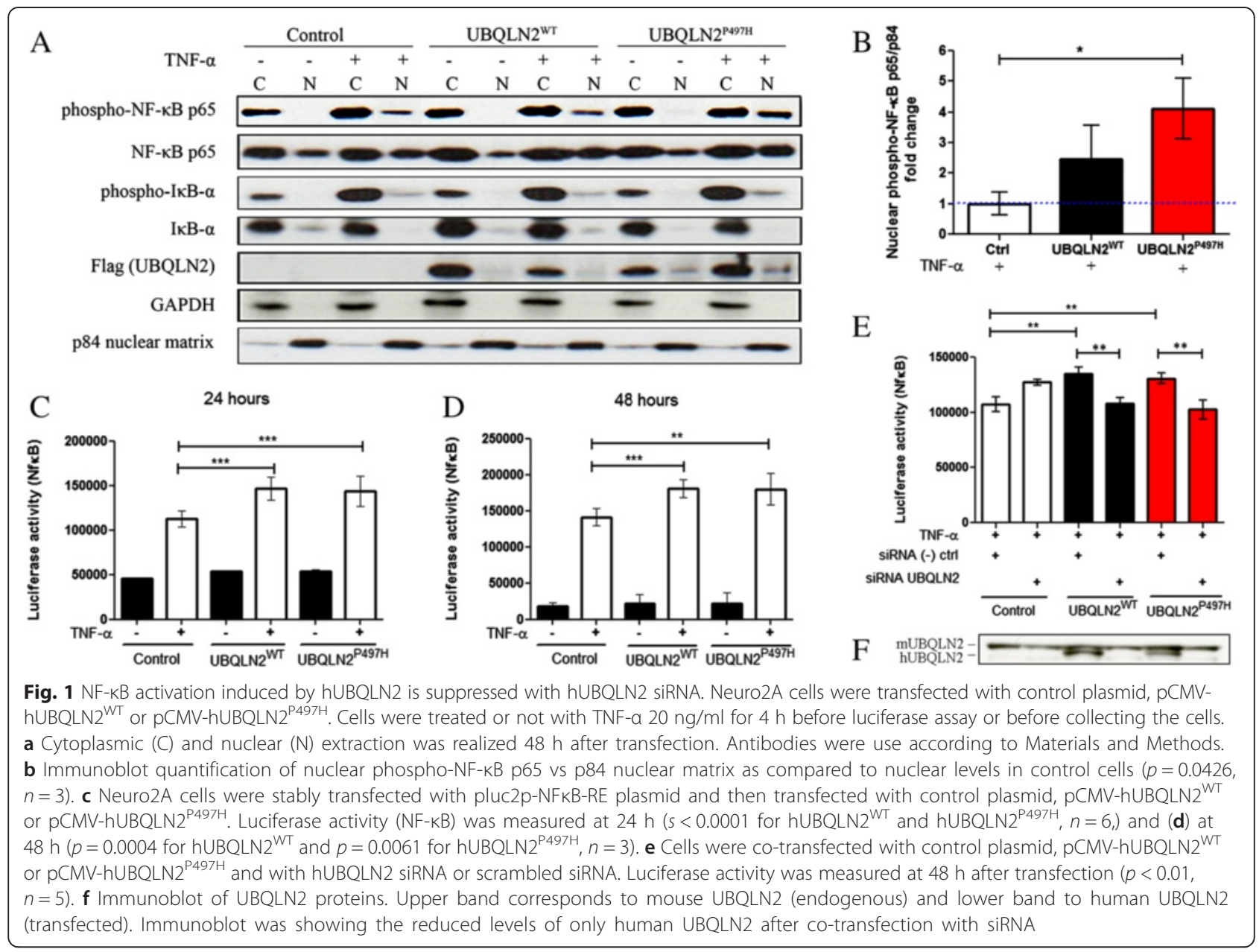

expresses luciferase when NF- $\mathrm{KB}$ is activated. $24 \mathrm{~h}$ after transfection and after $4 \mathrm{~h}$ of TNF- $\alpha(20 \mathrm{ng} / \mathrm{ml})$ treatment, both hUBQLN2 ${ }^{\mathrm{WT}}$ and hUBQLN2 ${ }^{\mathrm{P} 497 \mathrm{H}}$ showed a mean increase of 1.27 fold in luciferase activity $(p<0.0001)$ (Fig. 1c). $48 \mathrm{~h}$ after transfection and after $4 \mathrm{~h}$ of TNF- $\alpha(20 \mathrm{ng} / \mathrm{ml})$ treatment, again both hUBQLN2 ${ }^{\mathrm{WT}}$ $(p=0.0004)$ and hUBQLN2 ${ }^{\mathrm{P} 497 \mathrm{H}}(p=0.0061)$ expressing cells exhibited a mean increase of 1.28 fold in luciferase activity compare to control cells (Fig. 1d).

We used siRNA to validate the role of hUBQLN2 in $N F-\kappa B$ activation. The main idea was to down-regulate NF- $\kappa B$ activity by eliminating hUBQLN2 overexpression and aggregation. Three different siRNA, purchased from Origene (Rockville), were targeting human UBQLN2 gene. All three siRNA were efficient in down-regulating the levels of hUBQLN2 in Neuro2A cells and in abrogating formation of inclusions (data not shown). We transfected Neuro2A cells with siRNA SR309321A for $48 \mathrm{~h}$. $48 \mathrm{~h}$ after transfection, cells were treated with TNF- $\alpha$ for $4 \mathrm{~h}$ and luciferase activity was measured. Again, we detected an increase of NF-kB activity in both hUBQLN2 ${ }^{\mathrm{WT}}(1.26$ fold, $p<0.01)$ and hUBQLN2 ${ }^{\mathrm{P} 497 \mathrm{H}}$
(1.22 fold, $p<0.01$ ) transfected Neuro2A cells as compared to the control cells transfected with scrambled siRNA. When hUBQLN2 ${ }^{\text {WT }}$ or hUBQLN2 ${ }^{\text {P497H }}$ were co-transfected with siRNA SR309321A, luciferase activity decreased $(p<0.01)$ and came back to level noticed in control plasmid transfected cells (Fig. 1e). Scrambled siRNA do not recognize any sequences in either mouse or human genome. We measured human UBQLN2 level after siRNA/UBQLN2 co-transfection to assure the down regulation of hUBQLN2 (Fig. 1f). Endogenous mouse UBQLN2 levels were not reduced. These results suggest a role for hUBQLN2 in modulating NF- $\mathrm{kB}$ activation.

\section{UBQLN2 expression in Neuro2A cells leads to cellular stress via MAP kinase pathway}

We further investigated the cellular mechanisms which might explain NF- $\mathrm{kB}$ activation by UBQLN2. NF- $\mathrm{kB}$ can be activated by many different pathways [11]. Because most of these pathways are induced by membrane receptors, like Interleukine-1(Il-1), Toll-like receptor (TLR), tumor-necrosis factor receptor (TNFR) and growth 
factor receptor (GF-R), we examined intracellular pathways activated in context of cellular stress. Additionally, in Fig. 1, Neuro2A cells required to be stimulated by TNF- $\alpha$ to detect a significant NF- $k B$ activation induced by UBQLN2 up-regulation. These results suggest an involvement of TNF- $\alpha$ downstream pathway. We hypothesized that UBQLN2 up-regulation might constitute a cellular stress which may increases levels of MAP kinases and enhances their activation by TNF- $\alpha$. TNF- $\alpha$ receptor cascade activates numerous of signaling pathways, including p38 MAPK, p42/44 MAPK (ERK) and JNK/SAPK [19]. Each of these pathways can be activated by other mechanisms. JNK and p38 are mainly activated by cellular stress, such as inflammatory cytokines, UV, radiation, protein synthesis inhibitor, oxidative stress or ER-stress [20, 21] . ERK is more activated by growth factor, reactive oxygen species (ROS), ER-stress [22] and is also implicated in differentiation, memory and synaptic plasticity [23, 24]. All these kinases are implicated in NF- $\mathrm{kB}$ activation, making them suitable candidate for NF- $\mathrm{kB}$ activation by UBQLN2 [19].

To investigate if any of these pathways were activated by hUBQLN2, we transfected Neuro2A cells with control plasmid, pCMV-hUBQLN2 ${ }^{\mathrm{WT}}$ and pCMVhUBQLN2 ${ }^{\mathrm{P} 497 \mathrm{H}}$. We detected an increase in levels of phosphorylated MAPK in hUBQLN2 overexpressing cells. Figure $2 \mathrm{a}$ is showing the levels of these phosphorylated proteins (activated form) $48 \mathrm{~h}$ after transfection.

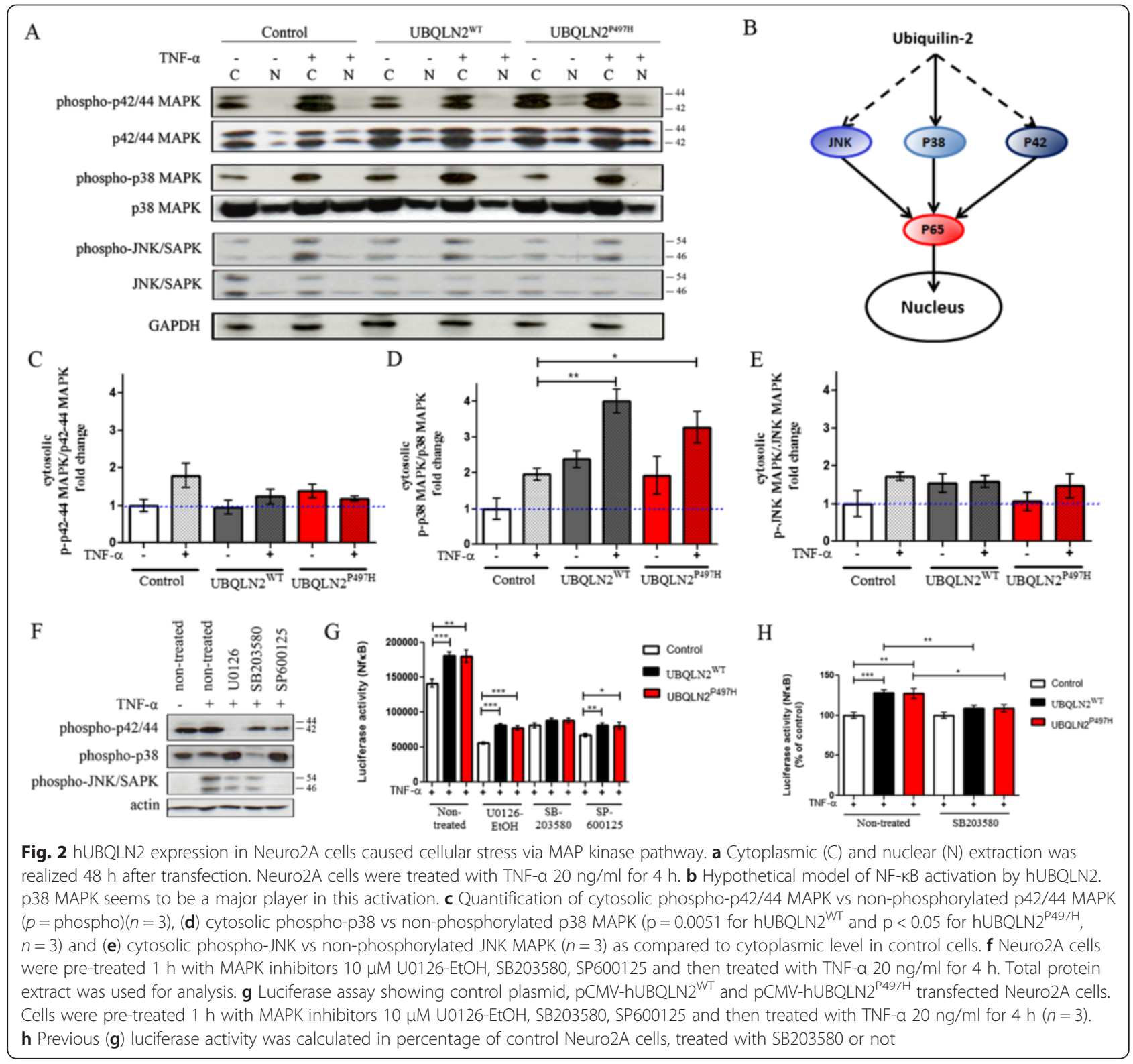


The levels of phospho-p42/44 MAPK were not different in cells expressing hUBQLN2 ${ }^{\mathrm{WT}}$ and hUBQLN2 ${ }^{\mathrm{P} 497 \mathrm{H}}$ as compared to control cells after TNF- $\alpha$ treatment (Fig. 2c). Moreover, there was a clear and significant increase of phospho-p38 in hUBQLN2 ${ }^{\mathrm{WT}}(\mathrm{p}=0.0051)$ and hUBQLN2P497H $(\mathrm{p}<0.05)$ transfected cells treated with TNF- $\alpha$ (Fig. 2d). However, we did not observed any increase in phospho-JNK/SAPK level compared to control (Fig. 2e). From these results, we can propose that UBQLN2 up-regulation leads to cellular stress via MAPK pathway.

To further elucidate which MAPK pathway is implicated in NF- $\mathrm{KB}$ activation by UBQLN2, we treated the cells with different specific MAPK inhibitors. Luciferase activity was measured at $1 \mathrm{~h}$ after inhibitor pretreatment and after $4 \mathrm{~h}$ of TNF- $\alpha$ treatment. We used U0126-EtOH, a selective p42/44 MAPK inhibitor, SB203580, a p38 MAPK inhibitor and SP600125, a selective JNK1/2/3 inhibitor. In comparison with U0126EtOH which was specific to p42/44 MAPK inhibition, SP600125 and SB203580 also partially inhibited p42/44 MAPK at a lower level than U0126-EtOH (Fig. 2f). We observed that all three kinase inhibitors led to partial decrease of NF-KB activity by the inhibition of their specific MAPK (Fig. 2f-g). After treatment with U0126$\mathrm{EtOH}$, we determined that NF- $\mathrm{kB}$ activity, as compared to control cells, was still significantly increased in hUBQLN2 ${ }^{\text {WT }}$ (1.46 fold, $\left.p<0.0001\right)$ and hUBQLN2 ${ }^{\text {P497H }}$ (1.38 fold, $p<0.0001$ ) transfected cells (Fig. 2g). Consequently, treating the cells with U0126-EtOH failed to inhibit UBQLN2-mediated NF- $\mathrm{KB}$ activation observed with TNF- $\alpha$ treatment alone (Figs. 1, 2g). We obtained almost the same results with SP600125 treatment. When Neuro2A cells were treated with this JNK inhibitor, there was still an increase of NF- $\mathrm{kB}$ activity in cells transfected with hUBQLN2 ${ }^{\mathrm{WT}}$ (1.21 fold, $\left.\mathrm{p}=0.0034\right)$ or with hUBQLN2 ${ }^{\text {P497H }}(1.20$ fold $p=0.0301)$ as compared to control cells. However, after treatment with SB203580, the NF- $\mathrm{KB}$ activity became similar between control cells and cells transfected with hUBQLN2 ${ }^{\text {WT }}$ (1.09 fold, $p=0.1052$ ) or hUBQLN2 ${ }^{\mathrm{P} 497 \mathrm{H}}$ (1.09 fold, $p=0.1690$ ) (Fig. 2g). When measured using percentage of control, NF- $\mathrm{kB}$ activity after SB203580 treatment was reduced by $19.2 \%$ in hUBQLN2 ${ }^{\mathrm{WT}}$ cells $(p=0.0038)$ and $18.7 \%$ in hUBQLN2 ${ }^{\mathrm{P} 497 \mathrm{H}}(p=0.0289) \quad$ (Fig. 2h). These results suggest that $\mathrm{p} 38$, but not $\mathrm{p} 42 / 44$ or JNK, was involved in enhancement of NF- $\mathrm{KB}$ activation by UBQLN2 upregulation.

\section{UBQLN2 promotes aggregation of ALS-linked proteins and cytoplasmic mislocalization of TDP-43}

We investigated a potential involvement of protein aggregation in cellular stress due to UBQLN2 expression. Protein inclusions are a pathological hallmark of ALS and other neurological disorders. Proteins such as TDP43, SOD1, P62 and FUS are components of these aggregates [25]. It has been shown with Neuro2A cells that co-transfection of UBQLN2 and c-terminal domain of TDP-43 cause aggregates of both proteins and that UBQLN2 seem to be more prone to aggregation than TDP-43 [4]. Furthermore, UBQLN2 ${ }^{\text {P506T }}$ co-localize with TDP-43 when injected in mouse with rAAV2/8 [26], but not in UBQLN2 $2^{\mathrm{P} 497 \mathrm{H}}$ transgenic mouse [27] or in UBQLN2 ${ }^{\text {P497H }}$ transgenic rats [28]. To elucidate this inconstancy and to clarify if hUBQLN2 aggregates can promote aggregation of endogenous TDP-43, we used different biochemical methods. First, we transfected Neuro2A cells with pCMV-hUBQLN2 ${ }^{\text {WT }}$ or pCMVhUBQLN2 $2^{\mathrm{P} 497 \mathrm{H}}$ to determine if inclusions were formed and if they exhibited ALS-like features with aggregated TDP-43 or p62 proteins and if positive for NF- $\mathrm{kB}$ associated proteins. Immunofluorescence microscopy revealed co-localization of UBQLN2, TDP-43 and p62 (as expected), but not co-localization of NF- $\mathrm{kB}$ p65 or IкB- $\alpha$ (Fig. 3b-c). Similar results were obtained when transfected cells were treated with TNF- $\alpha$ (data not shown). These data suggest the lack of direct interaction between UBQLN2 and NF-kB or IкB- $\alpha$.

UBQLN2 aggregation triggered a mislocalization of endogenous TDP-43 from nucleus to cytoplasm. Analyses of cytoplasmic and nuclear extracts revealed an increase in cytoplasmic TDP-43 in both hUBQLN2 ${ }^{\mathrm{WT}}$ and hUBQLN2 ${ }^{\text {P497H }}$ transfected cells compare to control, at $48 \mathrm{~h}$ after transfection (Fig. 3h). To further confirm the formation of aggregates, we have fractionated the soluble and insoluble proteins. There was significant increase of TDP-43 and p62 levels in insoluble fraction of hUBQLN2-expressing cells as compared to control cells (Fig. 3d, e, f). There was no increase of NF- $\mathrm{kB}$ or ІкB- $\alpha$ in the insoluble fraction of UBQLN2 cells. To examine if the cytosolic mislocalization of TDP-43 by UBQLN2 is time dependent, we performed live imaging of Neuro2A cells co-transfected with pFeGFP-hUBQLN2 ${ }^{\mathrm{P} 497 \mathrm{H}}$ and DsRED-TDP-43. We noted that at $24 \mathrm{~h}$ after transfection, TDP-43 was localized in the nucleus whereas UBQLN2 ${ }^{\text {P497H }}$ was detected in cytoplasmic inclusions. However, at $48 \mathrm{~h}$ after transfection, TDP-43 was colocalized with UBQLN2-positive inclusions (Fig. 3g). To assess whether the expression levels of hUBQLN2 in transfected Neuro2A were of physiological relevance, we compared the levels of UBQLN2 in transfected and nontransfected Neuro2A cells with UBQLN2 levels in nontransfected and transfected HEK293 cells. The immunoblotting results revealed that levels of hUBQLN2 in transfected Neuro2A cells were not in excess of endogenous mouse ubiquilin-2 levels or of endogenous human UBQLN2 levels in HEK293 cells (Fig. 3i). So, this suggests that small changes in UBQLN2 levels are 


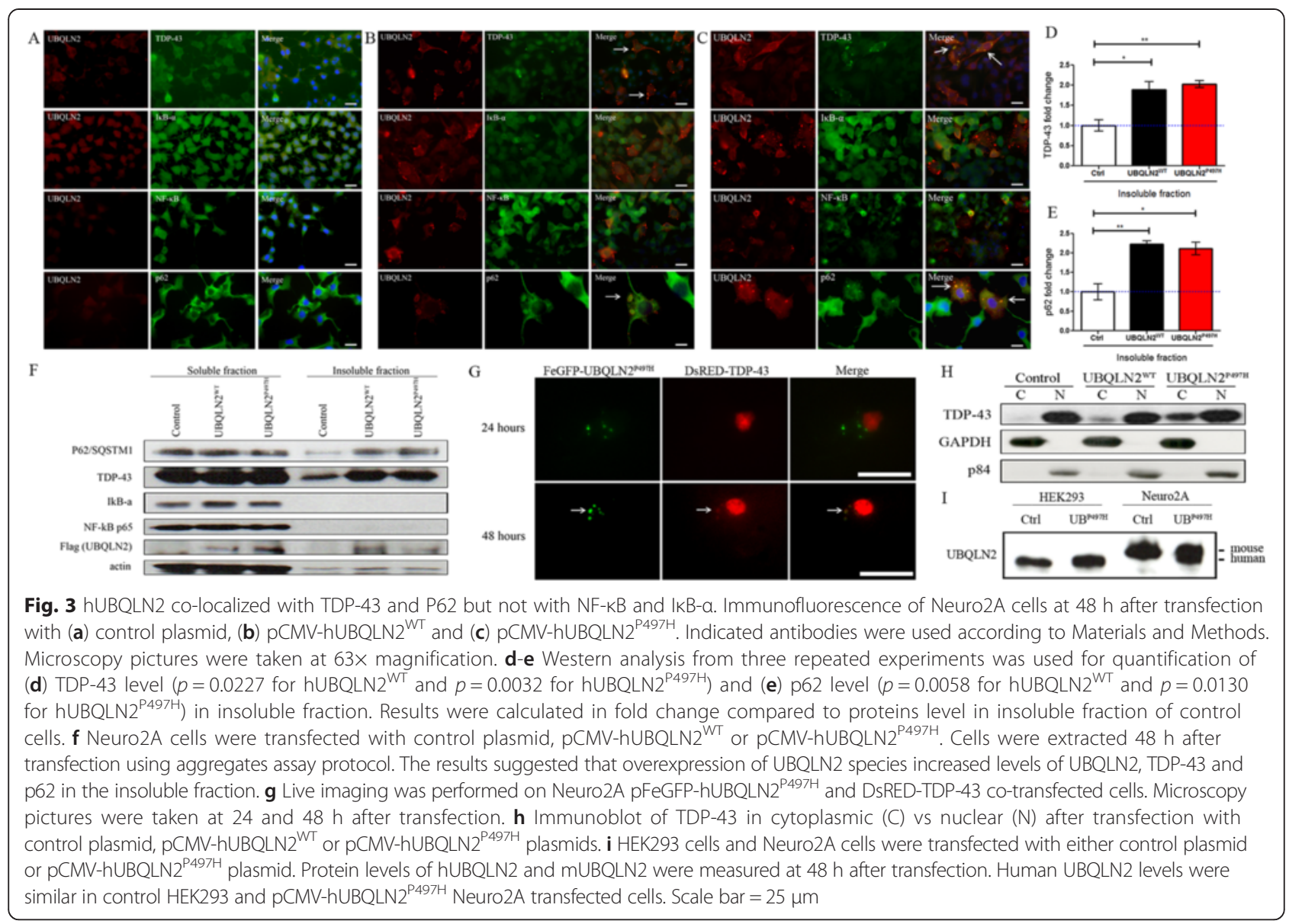

sufficient to promote cytosolic co-aggregation of UBQLN2, TDP-43 and p62. It should be noted that we did not detect TDP-43 aggregates in Neuro2A cell overexpressing only CMV-TDP-43 vector (Additional file 1 ).

\section{UBQLN2 aggregates are dynamic structures}

To visualize the formation of protein inclusions, we carried out a time-lapse microscopy imaging of Neuro2A cells transfected with pFeGFP-hUBQLN2 ${ }^{\mathrm{WT}}$ or pFeGFPhUBQLN2 ${ }^{\mathrm{P} 497 \mathrm{H}}$. A two hours imaging study carried out at $24 \mathrm{~h}$ after transfection revealed the dynamic nature of aggregates in hUBQLN2 transfected cells. Figure 4c shows merging aggregates over a $2 \mathrm{~h}$ period of time in pFeGFP-hUBQLN2 ${ }^{\text {P497H }}$ cells. We observed that smaller inclusions combined with bigger one (Additional file 2: Movie S1). To further investigate this phenomenon, we took pictures of fifty FeGFP-hUBQLN2 positive cells at 24 and $48 \mathrm{~h}$ and measured each aggregates size. The mean aggregates sizes were $69.22 \pm 4.032 \mathrm{RU}$ in UBQLN2 ${ }^{\mathrm{WT}}$ at $24 \mathrm{~h}$ and $213.9 \pm 12.99 \mathrm{RU}$ at $48 \mathrm{~h}$ after transfection (Fig. 4a, b). Similar results were obtained with hUBQLN2 ${ }^{\mathrm{P} 497 \mathrm{H}}(77.03 \pm 3.70$ and $203.1 \pm 13.87$ at 24 and $48 \mathrm{~h}$, respectively). We measured over 200 aggregates in each group and did not see significant difference in the number of aggregates per cell. The size difference between $24 \mathrm{~h}$ and $48 \mathrm{~h}$ was significant $(p<0.0001)$. We were also able to observe formation of aggregates after few hours of transfection, confirming that hUBQLN2 is prone to aggregation [4]. We also measured aggregates size when transfected with pCMV-hUBQLN2 (without GFP tag) and similar results were obtained. Aggregates merged and became bigger over time after transfection. These results suggest that, like stress granules, hUBQLN2 inclusions are dynamic in neurons and they can sequester TDP-43 in the cytosol.

\section{UBQLN2 up-regulation enhances vulnerability to}

\section{NF-KB-mediated neuronal death and causes an ER-stress}

To further examine whether aggregates of both hUBQLN2 $2^{\mathrm{WT}}$ and hUBQLN2 $2^{\mathrm{P} 497 \mathrm{H}}$ are associated with cellular stress with ensuing neuronal death, we monitored cell survival and apoptosis after UBQLN2 transfection. In ALS spinal cord, there is evidence of inverse correlation between ubiquitinated inclusions and the number of motor neurons, suggesting a link between aggregates and cell toxicity [29]. Moreover, NF-kB 


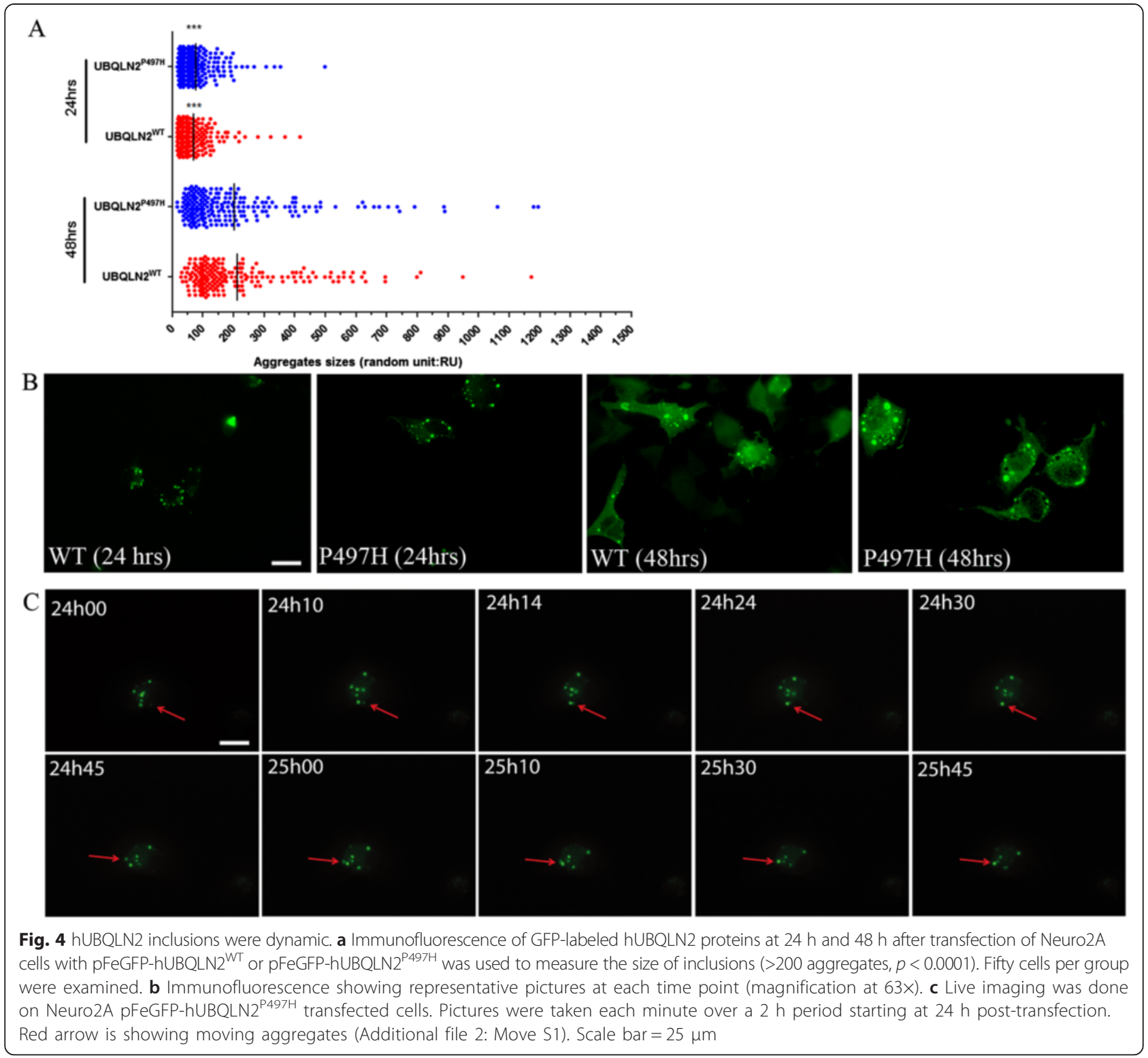

activation induced by TNF- $\alpha$ was found to induce motor neuron death in context of glutamate excitotoxicity [30]. Neuro2A cells were transfected with control plasmid vector, pCMV-hUBQLN2 ${ }^{\text {WT }}$ and pCMV-hUBQLN2 ${ }^{\mathrm{P} 497 \mathrm{H}}$ vectors. We then examined the activation of caspase-3, a marker of apoptosis. We observed that cleaved-Caspase3 was increased in UBQLN2 ${ }^{\text {WT }} \quad(\mathrm{p}=0.039)$ and UBQLN2 ${ }^{\text {P497H }} \quad(p=0.0167)$ transfected and TNF- $\alpha-$ treated cells after $48 \mathrm{~h}$ compared with control cells (Fig. 5a, b). Immunofluorescence microscopy showed that UBQLN2 positive cells were also positive for caspase-3 (Fig. 5f-h). We performed a MTS assay in transfected cells at $48 \mathrm{~h}$. The number of viable cells were decreased in both UBQLN2 ${ }^{\mathrm{WT}} \quad(\mathrm{p}=0.0144)$ and UBQLN2 ${ }^{\text {P497H }}(p=0.0067)$ transfected cells (Fig. 5i).
To assess the contribution of NF- $\mathrm{kB}$ activation to neuronal death of UBQLN2 overexpressed cells, we treated the cells with Withaferin A (WA), a known NF- $\mathrm{KB}$ inhibitor [31]. Neuro2A cells were pre-treated with WA $0.5 \mu \mathrm{M}$ for $2 \mathrm{~h}$ previous to TNF- $\alpha 20 \mathrm{ng} / \mathrm{ml}$ treatment. First, we observed in luciferase assay of non-transfected cells that WA decreased NF- $\mathrm{kB}$ activity by 2.5 times $(\mathrm{p}<0.0001)$ (Fig. $5 \mathrm{e}$ ). Again, we performed a MTS assay in transfected and WA treated cells and observed that Withaferin A succeeded to decreased mortality previously found in Neuro2A transfected cells (Fig. 5i). These results suggested that UBQLN2 enhanced vulnerability to neuronal death caused by TNF$\alpha$-mediated NF- $\kappa B$ activation.

We also looked at upstream caspase activation to clarify cellular mechanisms under this apoptosis induction. 


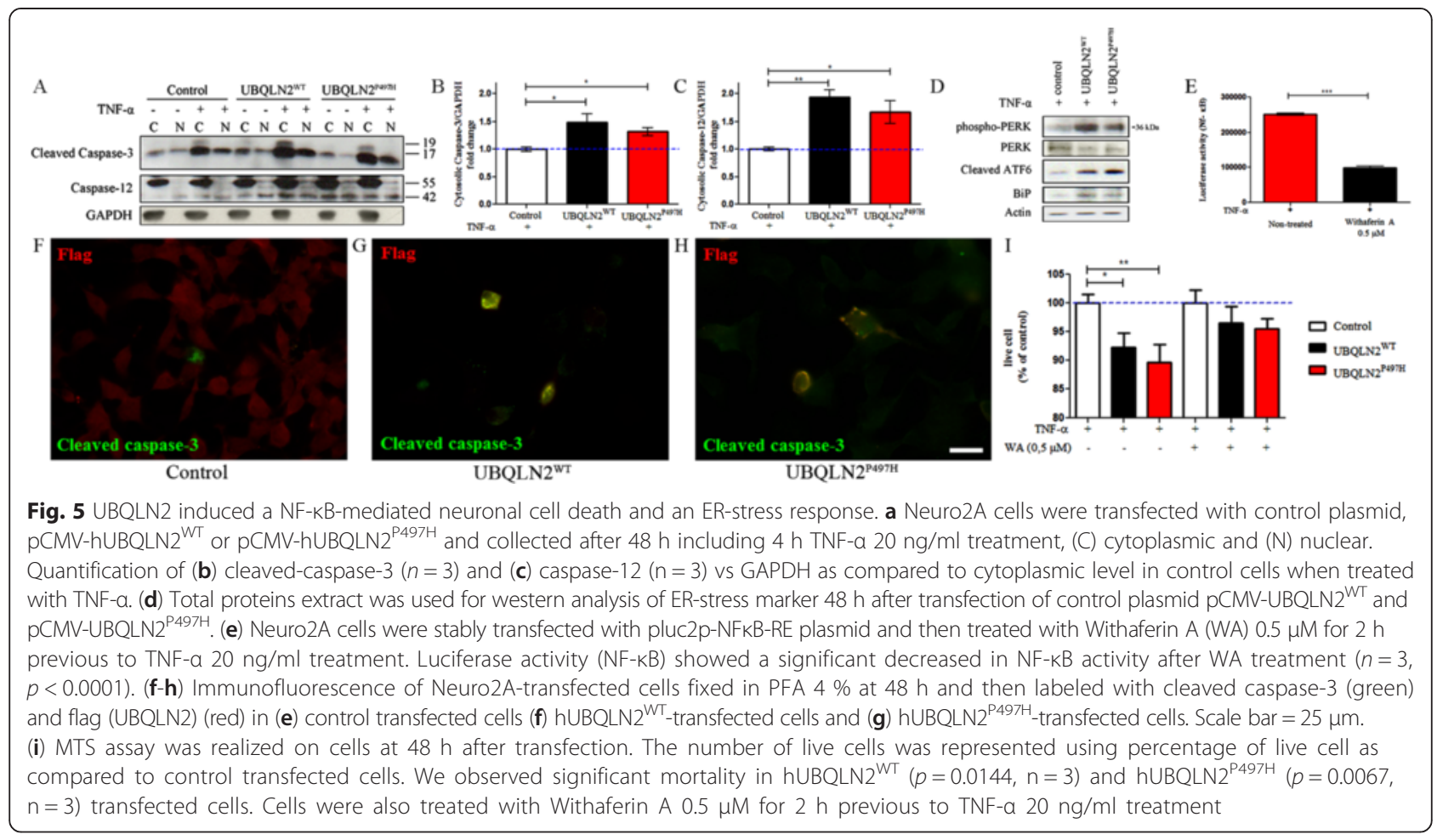

Cleaved-caspase-12, responsible for ER-stress-induced apoptosis, was increased in hUBQLN2 ${ }^{\mathrm{WT}}(\mathrm{p}=0.0023)$ and hUBQLN2 ${ }^{\mathrm{P} 497 \mathrm{H}}(\mathrm{p}=0.0309)$ transfected cells (Fig. 5a and $\mathrm{c}$ ). It has been shown that UBQLN2 mutation leads to proteasome impairment [4] and impairs endoplasmic reticulum-associated protein degradation (ERAD) [32]. Normally, ER proteins which fail to fold correctly are degraded by the $26 \mathrm{~S}$ proteasome but when proteasome is impaired, ER stress is induced by the accumulation of ERAD substrates [33]. To confirm if the caspase-12 increase can be explain by UBQLN2-mediated ER-stress, we quantified ER-stress markers.

Protein aggregates causing ER-stress leads to increased levels of Binding immunoglobulin protein (BiP), an ER chaperone. In circumstance of accumulation of unfolded proteins in the ER, BiP induces activation of different transmembrane proteins like protein kinase RNA-like endoplasmic reticulum kinase (PERK) or Activating transcription factor 6 (ATF6). BiP levels were increased in $\mathrm{hUBQLN} 2^{\mathrm{WT}}$ and in hUBQLN2 ${ }^{\mathrm{P} 497 \mathrm{H}}$ transfected Neuro2A (Fig. 5d). ATF6 is a membrane-anchored key transcription factor of the unfolded protein response (UPR) [34]. We observed an increase in cleaved fragment of ATF6 (36 kDa) in both hUBQLN2 ${ }^{\mathrm{WT}}$ and hUBQLN2 ${ }^{\mathrm{P} 497 \mathrm{H}}$. Phospho-PERK was also increased in UBQLN2 transfected cells. From these results, we can postulate that UBQLN2 aggregates (unfolded proteins) and ERAD degradation impairment [32] lead to BiP activation and $\mathrm{BiP}$ induced an ER-stress response.

\section{Discussion}

Here, we report that an upregulation of Ubiquilin-2 species can enhance NF- $\mathrm{kB}$ activity in neuronal cells. Many lines of evidence support this conclusion: (a) nuclear levels of NF- $\mathrm{kB}$ phospho-P65 were increased in Neuro2A cells overexpressing hUBQLN2 ${ }^{\mathrm{WT}}$ and hUBQLN2 ${ }^{\mathrm{P} 497 \mathrm{H}}$, and after TNF- $\alpha$ treatment (Fig. 1a, b); (b) luciferase reporter activity of NF- $\mathrm{kB}$ was also increased in cells overexpressing hUBQLN2 ${ }^{\mathrm{WT}}$ or hUBQLN2 ${ }^{\mathrm{P} 497 \mathrm{H}}$ (Fig. 1c, d); and (c) down-regulation of hUBQLN2 by the use of siRNA targeting hUBQLN2 succeeded in reducing NF- $\mathrm{BB}$ activity to its basal level (Fig. 1e). So, we detected significant increase of NF-kB activity by UBQLN2 species upregulation using three different approaches. It should be noted that an up-regulation of UBQLN2 alone was not sufficient to activate NF- $\mathrm{kB}$ and that Neuro2A cells required to be primed with TNF- $\alpha$.

These results are consistent with the view of a converging role for NF- $\mathrm{kB}$ in ALS pathogenesis. Several ALSlinked proteins were found to modulate the NF- $\mathrm{kB}$ pathway: TDP-43 upregulation can enhance NF- $\mathrm{kB}$ activation [14], mutation in valosin-containing protein (VCP) in mice resulted in NF- $\mathrm{kB}$ hyperactivation $[35,36]$ and suppression of Optineurin (OPTN) led to neuronal death via NF- $\kappa B$ pathway [37]. Fuse in Sarcoma (FUS) was found to enhance NF- $\mathrm{B}$ activation induced by physiological stress [38] and NF- $\kappa$ B-related inflammation was increased in mouse deficient in Progranulin (PGRN) [39]. Furthermore, there are reports that NF-kB 
inhibition by Withaferin A conferred neuroprotection in transgenic mouse models $[14,15]$.

Our findings that an up-regulation of UBQLN2 species enhances NF- $\mathrm{kB}$ activity in a TNF- $\alpha$ treatment dependent manner (Fig. 1) led us to investigate the cellular mechanisms underlying this activation. Evidence for MAPK implication came from the observation that: (a) phospho-p38 MAPK levels were increased in cells transfected with UBQLN2 species mainly with TNF- $\alpha$ treatment (Fig. 2a and d) and (b) there was inhibition of NF- $\mathrm{KB}$ activation due to UBQLN2 species by treatment with p38 inhibitor but not with p42/44 or JNK inhibitors (Fig. 2g, h). Thus, our results suggest an involvement of p38 MAPK in the enhancement of NF- $\mathrm{kB}$ activation by UBQLN2. Figure $2 b$ is showing a hypothetical model of NF- $\kappa B$ activation by UBQLN2 inclusions. Because phospho-p38 MAPK was robustly increased in UBQLN2 overexpressing cells and because its inhibitor SB203580 blocked a significant increase of NF- $\mathrm{kB}$ activity in UBQLN2 species-transfected Neuro2A cells, we propose that p38 is the main activator of NF- $\mathrm{kB}$ p65 due to UBQLN2 overexpression. This is the first report of NF- $k B$ activation via $\mathrm{p} 38$ MAPK pathway by an up-regulation of ALS-linked UBQLN2 mutant. This finding is in line with previous reports of up-regulation of p38 MAPK levels in motor neurons of SOD $1{ }^{\mathrm{G} 93 \mathrm{~A}}$ mice $[40,41]$.

A common pathological feature of ALS/FTD is the redistribution of TDP-43 from nucleus to cytoplasm in neurons of spinal cord and brain [42]. Here, we report that physiological (Fig. 3i) expression of hUBQLN2 ${ }^{\mathrm{WT}}$ or hUBQLN2 $2^{\mathrm{P} 497 \mathrm{H}}$ in Neuro2A can promote formation of cytoplasmic inclusions that progressively sequester TDP-43. The evidence is based on the immunolocalization of UBQLN2 and TDP-43 (Fig. 3a, c), the increased TDP-43 levels in insoluble fraction of Neuro2A transfected with UBQLN2 ${ }^{\mathrm{WT}}$ and UBQLN2 ${ }^{\mathrm{P} 497 \mathrm{H}}$ (Fig. 3d, e, f) and the increased levels of TDP-43 in the cytosol of Neuro2A cells overexpressing UBQLN2 species (Fig. 3h). These results are consistent with previous reports that ALS patients with UBQLN2 mutation are exhibiting UBQLN2 aggregates positives for TDP-43 $[4,5]$ and that UBQLN2 binds TDP-43 with high affinity [43]. A colocalization of either UBQLN2 ${ }^{\mathrm{WT}}$ or UBQLN2 $2^{\mathrm{P4} 97 \mathrm{H}}$ with c-TDP-43 has also been shown in Neuro2A cells cotransfected with c-TDP-43 and UBQLN2 [4] but not in UBQLN2 ${ }^{\mathrm{P} 497 \mathrm{H}}$ transgenic mouse [27] or in UBQLN2 ${ }^{\mathrm{P} 497 \mathrm{H}}$ transgenic rats [28]. This inconsistency can be explained by the low to moderate level of UBQLN2 protein in these in vivo models. It has been proposed that interaction and aggregation between UBQLN2 and TDP-43 is concentration dependent $[4,43]$. Indeed, we noted that TDP-43 was easier to detect in UBQLN2 aggregates at $48 \mathrm{~h}$ than $24 \mathrm{~h}$ after transfection which correlate to UBQLN2 aggregates sizes (Fig. 3g-4a).
So, factors in ALS which may contribute to cytosolic accumulation of UBQLN2 such as proteasome deficiency $[4,44]$ might also contribute to cytosolic TDP-43 accumulations. The early pathogenic mechanisms underlying TDP-43 recruitment to UBQLN2 inclusions has to be clarified. Recent report suggested that the binding of UBQLN2 to the C-terminal tail of TDP-43 reduces TDP-43 affinity for nucleic acids and may inhibit its physiologic function and increase its aggregation [43]. Another study has suggested that the oxidation of RRM1 domain of TDP-43 may cause protein aggregation [45]. Although, there is substantial evidence for oxidative stress in ALS physiopathology [46], it is still unknown whether UBQLN2 aggregation can cause oxidative stress which lead to TDP-43 RRM1 domain oxidation. However, we report that UBQLN2 up-regulation cause a cellular stress which leads to MAPK activation. Interestingly, kinases have been recently shown to have a critical role in TDP-43 accumulation in stress granules following a chronic stress [47]. The phosphorylation by kinases may modulate the association of TDP-43 with stress granules and, through a chronic process, could lead to the pathogenic aggregates find in ALS. Consequently, a time dependent recruitment of TDP-43 in UBQLN2 inclusions (Fig. 3g) could be explained in part by chronic kinases activation caused by UBQLN2 dysregulation.

We propose that UBQLN2 overexpression increased vulnerability to neuronal death. Many lines of evidence support this conclusion: (a) protein levels of cleaved caspase- 3 and caspase-12, an ER-stress related caspase, were increased in cells overexpressing UBQLN2 species when treated with TNF- $\alpha$ (Fig. 5a); (b) most of cleaved caspase-3 positive cells were positive for UBQLN2 (Fig. 5f, h); and (c) the number of living cells counted by MTS assay were decreased in Neuro2A transfected with $\mathrm{UBQLN2}^{\mathrm{WT}}$ or UBQLN2 ${ }^{\mathrm{P} 497 \mathrm{H}}$ (Fig. 5i). Moreover, we observed that UBQLN2-induced neuronal death can be decreased with WA treatment (Fig. 5i), which could suggest a role for NF- $\kappa B$ activation in neuronal death. We have previously shown that TDP-43 overexpression can enhance microglial toxicity toward neighboring neurons via NF- $\mathrm{kB}$ pathway and that NF- $\mathrm{kB}$ inhibition by Withaferin A treatment of TDP-43 mouse model reduces ALS disease symptoms [14]. Withaferin A also reduced levels of misfolded SOD1 and extended lifespan of mutant SOD1 ALS mice [15]. NF- $\mathrm{kB}$ is also known to modulates apoptosis in neurons treated with glutamate [48] or with chemicals inducing DNAdamage [49]. Our results are similarly consistent with previous studies with $\mathrm{UBQLN2} 2^{\mathrm{P} 497 \mathrm{H}}$ rats reporting neuronal loss in the cortex and dentate gyrus and a glial activation surrounding neuronal damages [28]. These results, taken together, suggest that the upregulation of UBQLN2 species can act like TDP-43 
toxicity in neurons and that neurons bearing UBQLN2 inclusions become more vulnerable to toxic mediator TNF- $\alpha$ secreted by activated microglia in context of inflammation.

There is evidence that mutations in UBQLN2 can slow down degradation of this protein $[4,44]$. Thus, such impairment of protein turnover can lead to an increase in the steady state levels of mutant UBQLN2. A similar post-transcriptional dysregulation in levels of WT UBQLN2 in ALS cases without genetic mutation cannot be excluded. Indeed, UBQLN2 accumulations have been detected in ALS patients without a mutation in the ubiquilin-2 gene [4]. Our observation that both WT and mutant UBQLN2 species can form inclusions when overexpressed in transfected Neuro2A cells (Fig. 3) are in line with data previously reported by Deng et al. [4].

\section{Conclusion}

In conclusion, our results suggest that dysregulation by up-regulation of UBQLN2 may contribute in part to sporadic and familial ALS pathogenesis through enhancement of NF- $\mathrm{kB}$ activation by $\mathrm{p} 38$ MAPK signaling and formation of inclusion bodies sequestering TDP-43. These pathways might represent suitable therapeutic targets for future ALS treatment.

\section{Methods}

\section{Cell culture, transfection and cell treatment}

Almost all experiments were done with Neuro2A cells, which are mouse neuroblastoma cells. Neuro2A cells were growth in Dulbecco's Modified Eagle Medium (DMEM) with $10 \%$ fetal bovine serum (FBS), $1 \%$ penicillin-streptomycin and $1 \%$ glutamine. Cells were transfected at 80-90 \% confluence with lipofectamine 2000 according to manufacturer protocol. Opti-MEM media was replaced by normal growth media $24 \mathrm{~h}$ after transfection. PCMV-hUBQLN2 ${ }^{\mathrm{WT}}$ and pCMVhUBQLN2 ${ }^{\mathrm{P} 497 \mathrm{H}}$ were used for transfection (see section plasmids construction). We used pCDNA3 as control plasmid. Cells were collected at $24 \mathrm{~h}$ or $48 \mathrm{~h}$ after transfection consistent with the experiment. Recombinant mTNF- $\alpha$ (R\&D systems, Minneapolis) treatment $(20 \mathrm{ng} / \mathrm{ml})$ was done $4 \mathrm{~h}$ before collecting the cells. HEK293 cells, which are human embryonic kidney cells, for Fig. 3i were cultured with same protocol as Neuro2A.

For kinase pathways investigation, MAPK specific inhibitors U0126-EtOH, SP600125 and SB203580 (ApexBio, Houston) dissolved at $1 \mathrm{mg} / \mathrm{ml}$ in DMSO were used at $10 \mu \mathrm{M}$ in a $1 \mathrm{~h}$ pre-treatment and then TNF- $\alpha(20 \mathrm{ng} / \mathrm{ml})$ was added to the cells for $4 \mathrm{~h}$. Human UBQLN2 siRNAs were purchased from Origene (catalog No: SR309321, Rockville). SiRNA SR309321A: rGrGrCrArGrCrUrCrAr UrUrArUrGrG rCrUrArArUrCrCrACA was used for the experiments. Cells were co-transfected with siRNA $(10 \mathrm{nM})$ and control plasmid, pCMV-hUBQLN2 ${ }^{\mathrm{WT}}$ or pCMV-hUBQLN2 ${ }^{\mathrm{P} 497 \mathrm{H}}$. NF-kB activation (luciferase assay) was measure at $48 \mathrm{~h}$ after transfection and after $4 \mathrm{~h}$ TNF- $\alpha$ treatment.

\section{Protein extraction and Western blot analysis}

After collecting the cells, cytoplasmic and nuclear extraction or total proteins extraction was realized. Cytoplasmic buffer contained $10 \mathrm{mM}$ HEPES pH 7.5, $10 \mathrm{mM}$ $\mathrm{KCl}, 1.5 \mathrm{mM} \mathrm{MgCl}_{2}, 0.34 \mathrm{M}$ sucrose, $10 \%$ glycerol, $1 \mathrm{mM}$ PMSF, $10 \mathrm{mM} \mathrm{NaF}$ and $1 \mathrm{mM} \mathrm{Na} \mathrm{VO}_{3}$. After ice lysis and low speed centrifugation, nuclear fraction was obtained with sonication in buffer containing $3 \mathrm{mM}$ EDTA, $0.2 \mathrm{mM}$ EGTA, $1 \mathrm{mM}$ PMSF, $10 \mathrm{mM}$ NaF, $1 \mathrm{mM}$ $\mathrm{Na}_{2} \mathrm{VO}_{3} .30 \mu \mathrm{g}$ of proteins was loaded into $10 \%$ SDSpage gels. Total protein was obtained with buffer containing $0.15 \mathrm{M} \mathrm{NaCl}, 0.05 \mathrm{M}$ tris $\mathrm{pH}$ 7.4, $10 \%$ glycerol and $1 \%$ Triton X-100. Cells were incubated on ice for $30 \mathrm{~min}$ and then centrifuged to collect the supernatant.

For aggregates assay, we first collected the cells at $48 \mathrm{~h}$ after transfection and dissolved them into a resuspending buffer containing $10 \mathrm{mM}$ tris, $1 \mathrm{mM}$ EDTA and $100 \mathrm{mM} \mathrm{NaCl}$. Then, we added same volume of extraction buffer 1 containing $10 \mathrm{mM}$ Tris, $1 \mathrm{mM}$ EDTA, $100 \mathrm{mM} \mathrm{NaCl}, 1 \% \mathrm{NP}-40$, protease and phosphatase inhibitor 1X. After sonication and high speed centrifugation (>100 $000 \mathrm{~g}$ ) for $5 \mathrm{~min}$, we kept the supernatant (soluble fraction). We added extraction buffer 2 containing $10 \mathrm{mM}$ Tris, $1 \mathrm{mM}$ EDTA, $100 \mathrm{mM} \mathrm{NaCl}, 0,5 \%$ $\mathrm{NP}-40$ and protease and phosphatase inhibitor $1 \mathrm{X}$ to the pellet 1 , sonicated and centrifuged again (>100 $000 \mathrm{~g}$ for $5 \mathrm{~min}$ ). After removing the supernatant, we extracted the pellet 2 with $10 \mathrm{mM}$ Tris, $1 \mathrm{mM}$ EDTA, $100 \mathrm{mM}$ $\mathrm{NaCl}, 0,5 \%$ NP-40, 0,25 \% SDS, 0,5 \% Deoxycholic acid and phosphatase and protease inhibitor 1X. Finally, we sonicated and kept supernatant 3 (insoluble fraction) [50].

Antibodies used were phospho-NF-кB p65 (Cell signaling, Whitby, 1:1000), NF-kB p65(Santa-cruz, Dallas, 1:1000), phospho-ІкB- $\alpha$ (Cell signaling, 1:1000), ІкB- $\alpha$ (Santa-Cruz, 1:1000), actin (Milipore, Etobicoke, 1:20,000), p84 nuclear matrix (Abcam, Cambridge, 1:1000), GAPDH (Abcam, 1:1000), TARDBP (Proteintech, Chicago, 1:2500), FLAG M2 (Sigma-Aldrich, Saint-Louis, 1:1000), UBQLN2 (Abcam, 1:1000), phospho-SAPK/JNK (Cell signaling, 1:1000), SAPK/JNK (Cell signaling, 1:1000), phospho-p42/44 (Cell signaling, 1:1000), p42/44 (Cell signaling, 1:1000), phospho-p38 (Cell signaling, 1:1000) p38 (Cell signaling, 1:1000), cleaved-caspase-3 (Cell signaling, 1:1000), caspase-12 (Cell signaling, 1:1000), phospho-PERK (Cell signaling, 1:1000), PERK (Sigma-Aldrich, 1:1000), ATF6 (Imgenex, 1:1000) and BiP (Cell signaling, 1:1000). 


\section{Luciferase assay}

Neuro2a cells were stably transfected with pGL4.32 [luc2p/NF-kB-RE/Hygro] (Promega, Madison) and then transfected with previous plasmids. After 24 or $48 \mathrm{~h}$, cells were lysed with glo lysis buffer (Promega, Madison) and 1 volume of Bright Glo luciferase assay system (Promega, Madison) was added after $5 \mathrm{~min}$. Each sample was duplicated and the experiments were repeated more than 5 times. Luciferase activity was measured with Enspire reading machine in a 96 wells plate.

\section{Immunofluorescence}

$48 \mathrm{~h}$ after transfection with pCMV-UBQLN2 ${ }^{\mathrm{WT}}$ and pCMV-UBQLN2 ${ }^{\mathrm{P} 497 \mathrm{H}}$, cells were fixed with $4 \%$ PFA and methanol on $10 \mathrm{~mm}$ coverslip. Goat serum $10 \%$ was used for blocking. First antibody was incubated overnight at $4{ }^{\circ} \mathrm{C}$ and $1 \mathrm{~h}$ at room temperature for secondary antibody. Primary antibodies were monoclonal Flag M2 (Sigma-Aldrich, Saint-Louis, 1:100), TARDBP (Proteintech, Chicago, 1:600), NF-kB p65 (Santa-Cruz, 1:200), IкB- $\alpha$ (Santa-Cruz, 1:200) and SQSTM1/P62 (Cell signaling, 1:200). Secondary antibodies were alexafluor 488 goat anti-rabbit (1:500) and alexa-fluor 594 goat anti-mouse (1:500).

\section{Plasmids construction}

Human UBQLN2 gene was obtained by PCR from RP11 human BAC: $43 \mathrm{~N} 15$. Gene was amplified using the primer 5'GGGGAATT CATGGACTACAAGGACGA CGATGACAA GGCTGAGAATGGCGAGAGCAGCG GC-3' (forward) and 5'-GGGGCGGCCGC TGGGGT GGGATAATCCTCCTAAAC-3' (reverse). The forward primer introduced an EcoRI restriction site and a flag tag in C-terminal. The reverse primer introduced a NotI restriction site. The $\mathrm{P} 497 \mathrm{H}$ mutation was introduced by mutagenesis. The PCR products were ligated into pCDNA3 plasmids with same restriction sites. The plasmids finally drove human UBQLN2 wild-type or $\mathrm{P} 497 \mathrm{H}$ mutant c-terminally fused to Flag under the control of a CMV promoter. We named these two plasmids pCMVhUBQLN2 ${ }^{\text {WT }}$ and pCMV-hUBQLN2 ${ }^{\mathrm{P} 497 \mathrm{H}}$.

To create a FeGFP-hUBQLN2 plasmid, we amplified UBQLN2 sequence from previous pCMV-UBQLN2 plasmids by PCR using the primer $5^{\prime}$-dGGGACGACG GATCCG CTGAGAATGGCGAGAGCAGCGGCCC-3' (forward) and 5'-dGGGACGACGCGG CCGCTTAC GATGGCTGGGAGCCCAG -3' (reverse). The forward and reverse primers introduced BamHI and NotI restriction sites without the flag tag in c-terminal. The PCR product was ligated into pCDNA3-Flag-eGFP plasmid with the same restriction sites. The plasmids finally drove human UBQLN2 c-terminally fused to Flag-eGFP under the control of a CMV promoter. We named these two plasmids pCMV-FeGFP-hUBQLN2 ${ }^{\mathrm{WT}}$ and pCMVFeGFP-hUBQLN2 ${ }^{\text {P497H }}$. Human wild type TDP-43 gene was used for DsRed-TDP-43 plasmid construction like previously described [51].

\section{MTS assay}

The number of live cells in proliferation was measured by MTS assay $48 \mathrm{~h}$ after transfection. Celltiter $96 \mathrm{AQ}_{\text {ueous }}$ One Solution Cell Proliferation Assay (Promega, Madison) was a colorimetric assay for determining the cell viability. MTS tetrazolium compound was reduced in a colored formazan by live cells. Cells were growth in a 24 wells plate. Live cells were washed with PBS X2 and then collected. We took $100 \mu \mathrm{l}$ of media and putted them in a 96 wells reading plate. $20 \mu \mathrm{l}$ of One solution Reagent was added and cells were incubated at $37^{\circ} \mathrm{C}$ for $1 \mathrm{~h}$. Absorbance was measured at $490 \mathrm{~nm}$. Viable cell was calculated by dividing absorbance in transfected cells by absorbance in nontransfected cells and then reported in percentage of control transfected cells. Cells were either treated or not with Withaferin A (Enzo Life Sciences) $0.5 \mu \mathrm{M}$ for $2 \mathrm{~h}$ and TNF- $\alpha 20 \mathrm{ng} / \mathrm{ml}$ was added to media for $4 \mathrm{~h}$.

\section{Live cell imaging}

Neuro2A cells were transfected with pCMV-FeGFPhUBQLN2 ${ }^{\mathrm{WT}}$, pCMV-FeGFP-hUBQLN2 $2^{\mathrm{P} 497 \mathrm{H}}$ or DsRedTDP-43. After $24 \mathrm{~h}$, opti-MEM was removed and replaced by DMEM $10 \%$ FBS. Cells were then putted in NIKON ECLIPSE TE2000-E live imaging system. Pictures were taken every $2 \mathrm{~min}$ over a $2 \mathrm{~h}$ period using Metamorph software.

\section{Statistical analysis}

Statistical significance was assessed using GraphPad Prism software. We used Student's unpaired $t$-test for generating the $\mathrm{p}$-values. We considered $\mathrm{p}<0.05$ as statistically significant.

\section{Additional files}

Additional file 1: Lack of cytoplasmic inclusions in neuro2A cells overexpressing TDP-43. Immunofluorescence of Neuro2A cells at $48 \mathrm{~h}$ after transfection with pCMV-TDP-43 vector only. TDP-43 is mainly expressed in nucleus. No TDP-43 aggregates were detected in cytosol of transfected cells. Scale bar $=25 \mu \mathrm{m}$. (JPEG $1482 \mathrm{~kb}$ )

Additional file 2: Movie S1. Movement and fusion of UBQLN2 inclusions in Neuro2A. Live imaging was performed on Neuro2A pFeGFP-hUBQLN2 ${ }^{\mathrm{P} 497 \mathrm{H}}$ transfected cells. Pictures of a single cell were taken each minute over a $2 \mathrm{~h}$ period starting at $24 \mathrm{~h}$ after transfection $(n=3)$. Neuro2A transfected with pFeGFP-hUBQLN2 ${ }^{\text {WT }}$ display the same aggregates movement. We observed different aggregates combining together over this period. Small aggregates seemed to all combined with the bigger aggregate. (AVI $467717 \mathrm{~kb}$ )

\section{Competing interests}

The authors declare no conflict of interest. 


\section{Authors' contributions}

J-PJ conceived and supervised this project. GS provided the DsRed-TDP-43, DP did construct the PCMV-UBQLN2 ${ }^{\text {WT }}$ and PCMV-UBQLN2 ${ }^{\text {P497H }}$ plasmids, KD performed some western blot analysis and all other experiments were realized by VP-M. VP-M and J-PJ analysed the data and wrote the paper. All authors read and approved the final manuscript.

\section{Acknowledgments}

This work was supported by the Canadian Institutes of Health Research. J.-P. J. holds a Canada Research Chair in neurodegeneration. We also want to thanks Dr. Ali Ayouaz for his helpful advices. The DsRed-TDP-43 plasmid was provided by Dr. Gen Sobue and Dr. Jun-Ichi Niwa.

\section{Author details}

${ }^{1}$ Research Centre of Institut Universitaire en Santé Mentale de Québec, Laval University, 2601 Chemin de la Canardière, Québec, QC G1J 2G3, Canada. ${ }^{2}$ Department of Psychiatry and Neuroscience, Laval University, 2601 Chemin de la Canardière, Québec, QC G1J 2G3, Canada. ${ }^{3}$ Department of Neurology, Nagoya University Graduate School of Medicine, 65 Tsurumai-cho Showa-ku, Nagoya 466-8550, Japan

\section{Received: 6 August 2015 Accepted: 22 October 2015}

\section{Published online: 31 October 2015}

\section{References}

1. Ajroud-Driss S, Siddique T. Sporadic and hereditary amyotrophic lateral sclerosis (ALS). Biochim Biophys Acta. 1852;2014:679-84.

2. Vucic S, Rothstein JD, Kiernan MC. Advances in treating amyotrophic lateral sclerosis: insights from pathophysiological studies. Trends Neurosci. 2014;37:433-42.

3. Zhang KY, Yang S, Warraich ST, Blair IP. Ubiquilin 2: a component of the ubiquitin-proteasome system with an emerging role in neurodegeneration. Int J Biochem Cell Biol. 2014;50:123-6.

4. Deng HX, Chen W, Hong ST, Boycott KM, Gorrie GH, Siddique N, et al. Mutations in UBQLN2 cause dominant X-linked juvenile and adult-onset ALS and ALS/dementia. Nature. 2011:477:211-5.

5. Williams KL, Warraich ST, Yang S, Solski JA, Fernando R, Rouleau G, et al. UBQLN2/ubiquilin 2 mutation and pathology in familial amyotrophic lateral sclerosis. Neurobiol Aging. 2012;33:2527. e3-10

6. Synofzik M, Maetzler W, Grehl T, Prudlo J, Vom Hagen JM, Haack T, et al. Screening in ALS and FTD patients reveals 3 novel UBQLN2 mutations outside the PXX domain and a pure FTD phenotype. Neurobiol Aging 2012:33:2949. e13-7.

7. Daoud H, Suhail H, Szuto A, Camu W, Salachas F, Meininger V, et al. UBQLN2 mutations are rare in French and French-Canadian amyotrophic lateral sclerosis. Neurobiol Aging. 2012;33:2230. e1-2230.e5.

8. Gellera C, Tiloca C, Del Bo R, Corrado L, Pensato V, Agostini J, et al. Ubiquilin 2 mutations in Italian patients with amyotrophic lateral sclerosis and frontotemporal dementia. J Neurol Neurosurg Psychiatry. 2013;84:183-7.

9. Massey LK, Mah AL, Ford DL, Miller J, Liang J, Doong H, et al. Overexpression of ubiquilin decreases ubiquitination and degradation of presenilin proteins. J Alzheimers Dis. 2004;6:79-92.

10. Rutherford NJ, Lewis J, Clippinger AK, Thomas MA, Adamson J, Cruz PE, et al. Unbiased screen reveals ubiquilin-1 and -2 highly associated with huntingtin inclusions. Brain Res. 2013;1524:62-73.

11. Vallabhapurapu S, Karin M. Regulation and function of NF-kappaB transcription factors in the immune system. Annu Rev Immunol. 2009;27:693-733.

12. Prell T, Lautenschlager J, Weidemann L, Ruhmer J, Witte OW, Grosskreutz J. Endoplasmic reticulum stress is accompanied by activation of NF-kappaB in amyotrophic lateral sclerosis. J Neuroimmunol. 2014;270:29-36.

13. Jiang YM, Yamamoto M, Kobayashi Y, Yoshihara T, Liang Y, Terao S, et al. Gene expression profile of spinal motor neurons in sporadic amyotrophic lateral sclerosis. Ann Neurol. 2005;57:236-51.

14. Swarup V, Phaneuf D, Dupre N, Petri S, Strong M, Kriz J, et al. Deregulation of TDP-43 in amyotrophic lateral sclerosis triggers nuclear factor kappaBmediated pathogenic pathways. J Exp Med. 2011:208:2429-47.

15. Patel $P$, Julien JP, Kriz J. Early-stage treatment with withaferin a reduces levels of misfolded superoxide dismutase 1 and extends lifespan in a mouse model of amyotrophic lateral sclerosis. Neurotherapeutics. 2014;12:217-33.
16. Frakes AE, Ferraiuolo L, Haidet-Phillips AM, Schmelzer L, Braun L, Miranda CJ, et al. Microglia induce motor neuron death via the classical NF-kappaB pathway in amyotrophic lateral sclerosis. Neuron. 2014;81:1009-23.

17. Olmos G, Llado J. Tumor necrosis factor alpha: a link between neuroinflammation and excitotoxicity. Mediators Inflamm. 2014;2014:861,231.

18. Kemler I, Fontana A. Role of IkappaBalpha and IkappaBbeta in the biphasic nuclear translocation of NF-kappaB in TNFalpha-stimulated astrocytes and in neuroblastoma cells. Glia. 1999:26:212-20.

19. Aggarwal BB. Signalling pathways of the TNF superfamily: a double-edged sword. Nat Rev Immunol. 2003;3:745-56.

20. Kyriakis JM, Banerjee P, Nikolakaki E, Dai T, Rubie EA, Ahmad MF, et al The stress-activated protein kinase subfamily of c-Jun kinases. Nature. 1994;369:156-60.

21. Anderson NG, Maller JL, Tonks NK, Sturgill TW. Requirement for integration of signals from two distinct phosphorylation pathways for activation of MAP kinase. Nature. 1990;343:651-3.

22. Boulton TG, Nye SH, Robbins DJ, Ip NY, Radziejewska E, Morgenbesser SD, et al. ERKs: a family of protein-serine/threonine kinases that are activated and tyrosine phosphorylated in response to insulin and NGF. Cell. 1991;65:663-75.

23. Sweatt JD. Mitogen-activated protein kinases in synaptic plasticity and memory. Curr Opin Neurobiol. 2004;14:311-7.

24. Johnson GL, Lapadat R. Mitogen-activated protein kinase pathways mediated by ERK, JNK, and p38 protein kinases. Science. 2002;298:1911-2.

25. Blokhuis AM, Groen EJ, Koppers M, van den Berg LH, Pasterkamp RJ. Protein aggregation in amyotrophic lateral sclerosis. Acta Neuropathol. 2013;125:777-94.

26. Ceballos-Diaz C, Rosario AM, Park HJ, Chakrabarty P, Sacino A, Cruz PE, et al. Viral expression of ALS-linked ubiquilin-2 mutants causes inclusion pathology and behavioral deficits in mice. Mol Neurodegener. 2015;10:25.

27. Gorrie GH, Fecto F, Radzicki D, Weiss C, Shi Y, Dong H, et al. Dendritic spinopathy in transgenic mice expressing ALS/dementia-linked mutant UBQLN2. Proc Natl Acad Sci U S A. 2014;111:14,524-9.

28. Wu Q, Liu M, Huang C, Liu X, Huang B, Li N, et al. Pathogenic Ubqln2 gains toxic properties to induce neuron death. Acta Neuropathol. 2014;129:417-28.

29. Giordana MT, Piccinini M, Grifoni S, De Marco G, Vercellino M, Magistrello M, et al. TDP-43 redistribution is an early event in sporadic amyotrophic lateral sclerosis. Brain Pathol. 2010;20:351-60.

30. Tolosa L, Caraballo-Miralles V, Olmos G, Llado J. TNF-alpha potentiates glutamate-induced spinal cord motoneuron death via NF-kappaB. Mol Cell Neurosci. 2011;46:176-86.

31. Oh JH, Lee TJ, Park JW, Kwon TK. Withaferin A inhibits iNOS expression and nitric oxide production by Akt inactivation and down-regulating LPS-induced activity of NF-kappaB in RAW 264.7 cells. Eur J Pharmacol. 2008:599:11-7.

32. Xia Y, Yan LH, Huang B, Liu M, Liu X, Huang C. Pathogenic mutation of UBQLN2 impairs its interaction with UBXD8 and disrupts endoplasmic reticulum-associated protein degradation. J Neurochem. 2013;129:99-106.

33. Lee AH, Iwakoshi NN, Anderson KC, Glimcher LH. Proteasome inhibitors disrupt the unfolded protein response in myeloma cells. Proc Natl Acad Sci U S A. 2003;100:9946-51.

34. Darling NJ, Cook SJ. The role of MAPK signalling pathways in the response to endoplasmic reticulum stress. Biochim Biophys Acta. 1843;2014:2150-63.

35. Badadani M, Nalbandian A, Watts GD, Vesa J, Kitazawa M, Su H, et al. VCP associated inclusion body myopathy and paget disease of bone knock-in mouse model exhibits tissue pathology typical of human disease. PLoS One. 2010:5.

36. Custer SK, Neumann M, Lu H, Wright AC, Taylor JP. Transgenic mice expressing mutant forms VCP/p97 recapitulate the full spectrum of IBMPFD including degeneration in muscle, brain and bone. Hum Mol Genet. 2010:19:1741-55.

37. Akizuki M, Yamashita $H$, Uemura K, Maruyama $H$, Kawakami $H$, Ito $H$, et al. Optineurin suppression causes neuronal cell death via NF-kappaB pathway. J Neurochem. 2013;126:699-704.

38. Uranishi $H$, Tetsuka $T$, Yamashita $M$, Asamitsu $K$, Shimizu M, Itoh M, et al. Involvement of the pro-oncoprotein TLS (translocated in liposarcoma) in nuclear factor-kappa B p65-mediated transcription as a coactivator. J Biol Chem. 2001;276:13,395-401. 
39. Yin F, Banerjee R, Thomas B, Zhou P, Qian L, Jia T, et al. Exaggerated inflammation, impaired host defense, and neuropathology in progranulindeficient mice. J Exp Med. 2010;207:117-28.

40. Tortarolo M, Veglianese P, Calvaresi N, Botturi A, Rossi C, Giorgini A, et al. Persistent activation of p38 mitogen-activated protein kinase in a mouse model of familial amyotrophic lateral sclerosis correlates with disease progression. Mol Cell Neurosci. 2003;23:180-92.

41. Holasek SS, Wengenack TM, Kandimalla KK, Montano C, Gregor DM, Curran GL, et al. Activation of the stress-activated MAP kinase, p38, but not JNK in cortical motor neurons during early presymptomatic stages of amyotrophic lateral sclerosis in transgenic mice. Brain Res. 2005;1045:185-98.

42. Neumann M, Sampathu DM, Kwong LK, Truax AC, Micsenyi MC, Chou TT, et al. Ubiquitinated TDP-43 in frontotemporal lobar degeneration and amyotrophic lateral sclerosis. Science. 2006;314:130-3.

43. Cassel JA, Reitz AB. Ubiquilin-2 (UBQLN2) binds with high affinity to the C-terminal region of TDP-43 and modulates TDP-43 levels in $\mathrm{H} 4$ cells: characterization of inhibition by nucleic acids and 4-aminoquinolines. Biochim Biophys Acta. 1834;2013:964-71.

44. Chang L, Monteiro MJ. Defective proteasome delivery of polyubiquitinated proteins by ubiquilin-2 proteins containing ALS mutations. PLoS One. 2015;10, e0130162

45. Chang CK, Chiang MH, Toh EK, Chang CF, Huang TH. Molecular mechanism of oxidation-induced TDP-43 RRM1 aggregation and loss of function. FEBS Lett. 2013:587:575-82

46. Barber SC, Shaw PJ. Oxidative stress in ALS: key role in motor neuron injury and therapeutic target. Free Radic Biol Med. 2010;48:629-41.

47. Meyerowitz J, Parker SJ, Vella LJ, Ng D, Price KA, Liddell JR, et al. C-Jun Nterminal kinase controls TDP-43 accumulation in stress granules induced by oxidative stress. Mol Neurodegener. 2011;6:57.

48. Pizzi M, Sarnico I, Boroni F, Benetti A, Benarese M, Spano PF. Inhibition of IkappaBalpha phosphorylation prevents glutamate-induced NF-kappaB activation and neuronal cell death. Acta Neurochir Suppl. 2005;93:59-63.

49. Aleyasin H, Cregan SP, Iyirhiaro G, O'Hare MJ, Callaghan SM, Slack RS, et al. Nuclear factor-(kappa)B modulates the p53 response in neurons exposed to DNA damage. J Neurosci. 2004;24:2963-73.

50. Karch CM, Borchelt DR. A limited role for disulfide cross-linking in the aggregation of mutant SOD1 linked to familial amyotrophic lateral sclerosis. J Biol Chem. 2008;283:13,528-37.

51. Iguchi Y, Katsuno M, Takagi S, Ishigaki S, Niwa J, Hasegawa M, et al. Oxidative stress induced by glutathione depletion reproduces pathological modifications of TDP-43 linked to TDP-43 proteinopathies. Neurobiol Dis. 2012:45:862-70

\section{Submit your next manuscript to BioMed Central and take full advantage of:}

- Convenient online submission

- Thorough peer review

- No space constraints or color figure charges

- Immediate publication on acceptance

- Inclusion in PubMed, CAS, Scopus and Google Scholar

- Research which is freely available for redistribution

Submit your manuscript at www.biomedcentral.com/submit 